\title{
El Blog como Herramienta Didáctica en el proceso de Enseñanza Aprendizaje de Estudios Sociales
}

\author{
Use of Blog as a Didactic Tool in the Teaching Learning Process of Social Studies
}

Christian Troya Torres. ${ }^{1}$, Juan Carlos Quishpe Cusi. ${ }^{2}$, Fidel Parra Balza. ${ }^{3}$

\begin{abstract}
.
In recent times the technology has come to change some ways of thinking in human beings, in ancient times it was very rudimentary, with the appearances of instruments which man could have changed life on earth over the years were born the technologies and this came to evolve the world everything is now very fast and very modern, education is part of the modern changes, the classes were taught in a classroom of slate and ink markers, now see as digital tools have legacy to incorporate new learning s process where there is active participation and interaction between teachers, students and society in general. That is why there is this scientific article, with the aim of creating an educational Blog as a teaching tool to enhance educational processes in the field of social studies for students in ninth year of the Educational Unit "Juan Montalvo" of the City of Quito, Ecuador. Its methodological development was based on techniques such as observation, survey, the index cards, lincografias, hemerografias and mnemonics, which helped in the creation, design and structure of the blog, as well as the registration of information in the platform and validation of the resource according to the perspective of teachers and students. According to the results, it was concluded that teachers considered useful implementation of the educational blog, for the support and strengthening, which provides to the learning process; while students showed motivation in carrying out the activities, through interaction with the platform and learning in the achievement of the knowledge community.
\end{abstract}

Keywords: ICT, mechanical devices, instructive procedure, blog, Educational Blog, Social Studies, innovative training

\footnotetext{
${ }^{1}$ Unidad Educativa Juan Montalvo. christian.troya@educacion.gob.ec

${ }^{2}$ Colegio Fiscal Profesor Pedro Echeverría Terán. juanc.quishpe@educacion.gob.ec

${ }^{3}$ Universidad Tecnológica Israel. fparra@uisrael.edu.ec
} 


\section{Resumen.}

En los últimos tiempos la tecnología ha llegado a cambiar algunas formas de pensamiento en los seres humanos, en la antigüedad todo era muy rudimentario, con el aparecimiento de instrumentos que el hombre pudo cambiar la vida en la tierra con los años nacieron las tecnologías y esto llegaron a evolucionar el mundo entero ahora todo es muy rápido y muy moderno ,la educación forma parte de esos cambios modernos, las clases eran impartidas en un salón de con pizarra y marcadores de tinta, ahora vemos como las herramientas digitales han llegado a incorporar nuevos proceso $\mathrm{s}$ de aprendizaje donde existe la participación activa e interacción entre docentes, estudiantes y sociedad en general. Es por eso se plantea el presente artículo científico, con el objetivo de crear un Blog Educativo como herramienta didáctica para mejorar los procesos educativos en la materia de Estudios Sociales para estudiantes de noveno año de la Unidad Educativa "Juan Montalvo" de la ciudad de Quito, Ecuador. Su desarrollo metodológico se fundamentó en técnicas como la observación, la encuesta, las fichas bibliográficas, lincografías, hemerografías y mnemotécnicas, que ayudaron en la creación, diseño y estructuración del blog, así como en el registro de la información en la plataforma y la validación del recurso según la perspectiva de docentes y estudiantes. Según los resultados, se concluyó que los docentes consideraron útil la implementación del blog Educativo, por el apoyo y fortalecimiento, que proporciona al proceso de aprendizaje; mientras que los estudiantes mostraron motivación en la realización de las actividades, a través de la interacción con la plataforma y la comunidad de aprendizaje en el logro del conocimiento.

Palabras claves: TIC, herramientas tecnológicas, proceso educativo, blog, Blog Educativo, Estudios Sociales, educación tecnológica

\section{Introducción}

Cabe recalcar que vivimos en un mundo donde la tecnología ha llegado demasiado rápido y que han originado notables transformaciones en la sociedad, una de ellas consideramos a la tecnología en los procesos de aprendizaje, lo cual permite que se integren nuevos modelos educativos. Por esta razón, su aparición representa una de las mayores revoluciones educativas, culturales y sociales; ocurridas en el transcurso de los últimos años y se considera que su rango de acción está mundializado y muy desarrollado

No obstante, pese a los esfuerzos que se han realizado en Ecuador para dotar de recursos tecnológicos a las escuelas, el sistema educativo sigue siendo tradicional, repetitivo y memorístico, razón por la cual los estudiantes considerados nativos digitales, pierden el interés por aprender. Por otra parte, los docentes en su mayoría migrantes digitales, sienten un miedo normal y rechazo a la utilización de herramientas digitales. En este sentido, de continuar con esa situación puede presentarse problemas en los diferentes procesos de aprendizaje y sobre todo en las habilidades y destrezas donde se deben desarrollar según las necesidades del siglo XXI, las cuales están relacionadas con las nuevas tendencias tecnológicas. 
Es por estas razones, se propone la presente investigación, con el objetivo de crear un Blog Educativo como herramienta didáctica en el proceso de aprendizaje en la asignatura de Estudios Sociales en los estudiantes de noveno año de la Unidad Educativa "Juan Montalvo" de la ciudad de Quito, Ecuador. La misma se planteó con la finalidad de ofrecer una alternativa dirigida a favorecer la realidad expuesta, la cual representa un recurso de avanzada para el docente y para el estudiante.

Este recurso tecnológico, es considerado parte de los fenómenos más nuevos y enriquecedores disponibles en la red, ya que es una herramienta tecnológica de comunicación novedosa, cuyas bondades se extienden también al poder crearse de forma gratuita y su utilización no requiere tener habilidades informáticas particulares. Es una nueva forma de comunicarse que permite publicar textos, imágenes, sonidos, enlaces en un solo recurso; aplicado al proceso educativo, su uso se enfoca en los procesos centrados en el sujeto, de construcción de significados, de compartir saberes y de aprendizaje colaborativo y participativo, donde cada participante es depositario y artífice del conocimiento (Buxarrais, 2016).

En este orden de ideas, al incorporar el blog como herramienta tecnológica educativa, se contribuirá al proceso formativo desarrollado en la Educación General Básica Superior, una etapa importante y fundamental en la vida de toda persona pues en su transcurso se aprende a ser responsable, a tener valores, a constituirse como individuo y a la adquisición de conocimientos, que le permitirán desenvolver como una persona que aporta a la sociedad y en el contexto en el cual un aprendiz debería desempeñarse a futuro. Lo cual enlaza claramente con los Estudios Sociales en la Educación, área que busca lograr en los estudiantes, el alcance de una perspectiva general de la sociedad a la cual pertenecen, conocer su origen y evolución histórica; así mismo conocer los valores ciudadanos, lo que les permitirá el desarrollo de destrezas y reconocimiento de otros campos del aprendizaje.

El contexto de estudio fue la Unidad Educativa Juan Montalvo, una institución creada básicamente para la formación indispensable de alumnos a través de valores y orientación. En cuanto a la población, se tomaron 100 estudiantes de cursantes de noveno año, en el período académico 20182019. La muestra se seleccionó con criterio no probabilístico, se realizó intencionalmente a juicio del investigador, de lo cual la integraron 4 profesores del área de Estudios Sociales y 35 alumnos cursantes de noveno año; quienes fueron elegidos como representativos o típicos de la población. La escogencia del grupo de estudio tomó en cuenta la visión de género en igual proporción; aplicándose para la recolección de información, la encuesta y la entrevista a profundidad, cuyos resultados fueron procesados con la estadística descriptiva, particularmente mediante herramientas digitales que nos sirvieron para realizar una encuesta y de allí sacar los resultados , que arrojó información, la cual para su interpretación y análisis fue presentada en forma de cuadros y gráficos, cuyos resultados fueron discutidos y permitieron concluir el trabajo y corroborar el cumplimiento del estudio planteado para el presente artículo. 


\section{Metodología}

Podemos encontrar varias razones al hablar de estudios sociales ya que esta asignatura nos ayuda hacer seres humanos con pensamiento crítico y conocer mediante la difusión de ciencias multidisciplinarias, algunos aspectos que el ser humano tuvo que realizar para poder descubrir grandes cosas y lograr realizarlas, el estudio de las ciencias sociales tiene también como importancia profundizar el ámbito social, político, y cultural del mundo y hoy en día cada vez nos enfrentamos a los grandes eventos que se están suscitando en el mundo por los sistemas radicales de gobierno.

\section{Estudios Sociales}

Los retos que en la actualidad se han dado dentro del proceso de enseñanza y aprendizaje en la asignatura de Estudios Sociales, permiten asumir que no basta con contar la historia a través de los tiempos, y como cada personaje según la época iba aportando grandes cambios a la sociedad es por eso que todas estas ciencias multidisciplinarias que están relacionadas con la materia, ayudan a que los jóvenes visualicen sus propias ideas, sus valores y de poder enfrentarse a una sociedad muy cambiante

A la hora de aprender contenidos de la asignatura se aplicado diferentes estrategias metodológicas que nos han ayudado a que los alumnos observen de mejor manera su mundo, métodos como los grandes viajes, visitas a museos, o monumentos nos han trasladado a que esta asignatura se aprenda de mejor manera

Así mismo, lograr que los jóvenes de "realicen una reflexión ordenada y comprensiva acerca de su acontecer individual, inmerso y condicionado por el entorno social, cuya realidad original es el resultado de un acontecimiento histórico" (Ordoñez, Perez, and Rzonzew, 2016). De tal manera que los alumnos a través del conocimiento adquirido en las ciencias sociales reflexionan sobre su realidad, toma conciencia de que pueda mejorarla modificarla, observar y manejar la realidad.

\section{Proceso de enseñanza y aprendizaje en estudios sociales.}

En las distintas formas de explicar el cómo se debe aprender ciencias sociales debemos apuntar a la formación de los individuos, contribuyendo para que desarrollen y adquieran capacidades que les permitan manejarse en todos los ámbitos, "es por eso que aprender en esta área del conocimiento, significa aprender a saber y saber hacer, a convivir y saber ser una persona responsable y comprometida socialmente" (Fernández, García y Santisteban, 2012, p.13).

En este sentido, el propósito de enseñar en estudios sociales ha de ser una acción contra socializadora, es decir, de preparar a los estudiantes para que construyan su propio conocimiento, se ubiquen en su mundo y estén preparados para intervenir en él de una manera justa, equitativa y equilibrada. Se reclame formar dentro de la coherencia "entre el pensamiento y la acción, garantizando que el protagonismo de los jóvenes en la construcción del mundo individual y social, 
se base en valores alternativos, fundamentados en el compromiso, la justicia, la tolerancia y la solidaridad". (Osorio and Díez, 2017).

Siendo esto, una forma social de ver el mundo a través de diferentes perspectivas, es decir, todos los seres humanos deben establecer acuerdos por medio del dialogo que faciliten una sana convivencia y una mejor relación entre las personas, proporcionando espacios de reflexión, participación y encuentros de formación ciudadana.

En este sentido, la asignatura de Estudios sociales está vinculada a la representación de la realidad social en diferentes escenarios y épocas. El conocimiento en esta área ha sido permitir que los estudiantes aprendan y analicen la situación política y socioeconómica de su país, proporcionen fondos para que sean más significativo en el mundo, para que puedan asumir el papel de ciudadanos con principios y formación que contribuyan al establecimiento de una mejor sociedad.

\section{Las TIC en el proceso de enseñanza y aprendizaje en Estudios Sociales}

La importancia que tienen las herramientas digitales en el proceso educativo, radica justamente en su conceptualización, la cual consiste en el "conjunto de técnicas, desarrollo y dispositivos avanzados derivados de las nuevas herramientas (software y hardware), soportes de la información y canales de comunicación que integran funcionalidades de almacenamiento, procesamiento y transmisión digital de la información” (Hernández, 2017).

Corroborando esto señalamientos, González (2018) se refiere a que las Tecnologías de la información y comunicación corresponden a diferentes usos que hoy en día los jóvenes utilizan para diversas actividades tanto educativas como culturales, existen diferentes herramientas que nos han permitido trabajar de manera eficiente y corroborar a los grandes avances que se están dando. La tercera razón es la pedagógica que se centra en el rol del uso de las TIC en los procesos de formación académica, en la materia de Estudios Sociales, de manera particular la tecnología de la información y comunicación, ha demostrado que puede ampliar las oportunidades de aprendizaje, ya que aportan datos de realismo y actualidad.

Cabe mencionar lo señalado por Arteaga (2019) que las TIC, hacen asequible el conocimiento y la autogestión del mismo; además, constituyen un factor de interés y motivación para el estudiante, al encontrar más información acerca de las tareas de manera divertida y menos tediosa. Paralelo a ello, el empleo de las TIC, es una cuestión que genera expectativas en la comunidad educativa y de forma adicional otorga un nivel cualitativamente superior al trabajo en el seno de la institución educativa.

En función de ello, el uso de las TIC en el área de Estudios Sociales, presenta relevancia pues cumple como medio para comunicar y hacer accesible la información tanto individual y grupal, a la vez que permite dinamizar el rol del docente en el aula. En este propósito, se pueden mencionar varios recursos que pueden utilizarse con el uso de la tecnología y que para los estudiantes resulta de gran ayuda en su progreso académico y que les resulte motivador en esta área, como: mapas, enciclopedias, imágenes multimedia, entre otros. 
El blog educativo como herramienta didáctica para el proceso de enseñanza de Estudios Sociales.

De esta forma el blog como herramienta didáctica para el aprendizaje, viene a ser una de una comunicación asincrónica de la Web 2.0, que nos ayuda a enlazar varios artículos, documentos e imágenes y videos que ayudan al proceso académico de los alumnos.

Bajo esta condición, se puede plantear su uso, al respecto Rodríguez \& Mulet (2016) comentan que los blogs "ofrecen una herramienta diferente y el potencial para reinventar el trabajo que se realiza con los diarios de papel en el aula de clase, retando a estudiantes y maestros a pensar en formas de escribir auténticas" (p. 75).

Según los planteamientos de diversos autores el blog en la educación, puede ser aprovechado en diferentes ámbitos como: contenido hipertextual y multimedia: el blog permite alojar cualquier tipo de archivos multimedia: videos, textos, imágenes, audios, animaciones flash, admite también enlaces a documentos u otros sitios web. De igual manera el blog ayuda a que los seres humanos sean más eficientes y, sobre todo, sus tareas lo realicen de manera más dinámica y rápida, no es necesario investigar en otras fuentes, el blog les ayuda como un sitio o repositorio de información. Se tiene que las entradas a los blogs se organizan de manera que cada uno de los alumnos pueda ingresar en cada enlace y pueda investigar su tarea, también los contenidos son apropiados ya que se los puede leer con facilidad y también descargarlos

En cuanto a la relación con otras aplicaciones en la red, los blogs se pueden conectar con otro tipo de aplicaciones o herramientas que necesiten su ingreso para desarrollar su actividad. de igual manera se puede mencionar que el blog educativo como herramienta didáctica de la web 2.0 sirve para dar agilidad a las tareas de los alumnos, donde cada uno de ellos se encontrará con enlaces, páginas, o entradas muy diferentes y también podrán compartir con el resto de la comunidad virtual.

En este mismo orden de ideas, las ventajas que esta herramienta ofrece a los educadores según lo expuesto por Zallas, Choquijimse, Falcón, \& Solano (2018), se encuentra que el blog permite el paso de la clase magistral al ambiente tecnológico y de poder interactuar con los estudiantes; facilita la publicación de forma inmediata de archivos enlaces y videos relacionados a temas de interés en cualquier asignatura, así como la presentación de tareas y actividades, revisión y evaluación de las mismas.

Cabe agregar, que para los estudiantes la creación de espacios electrónicos como el blog, ofrece múltiples oportunidades, que según Rodríguez y Mulet (2016), ayudan al mejoramiento de la escritura, el intercambio de ideas; optimizar los contenidos académicos, enriqueciéndolos con elementos multimedia como imágenes, videos, animaciones, sonidos u otra Web 2.0.; dejar comentarios en cada post, permitiendo así el diálogo y el debate entre docentes y estudiante; implicarse en su aprendizaje y no ser solo receptor de información, sino que se convierte en emisor de la misma, como participantes activos. 
De igual modo, otra de las ventajas más importantes que menciona Manso (2013) respecto al manejo del blog, es la posibilidad de eliminar el uso del papel como único medio para registrar, redactar y escribir información, para ser reemplazado por un espacio electrónico que permite la escritura y el uso de elementos multimedia como: videos, sonidos, imágenes, animaciones y el almacenamiento de información en orden cronológico, la cual puede ser consultada en forma diferida en cualquier momento.

De tal forma, que la implementación del blog como herramienta didáctica, es en gran medida un recurso tecnológico eficiente que presenta múltiples y eficientes funciones y aplicaciones que favorecen el proceso educativo; sin embargo, aún en la actualidad representa un desafío para numerosos docentes puesto que muchos no conocen su potencial. Es por ello en lo que radica su importancia al proponer su uso como herramienta didáctica para el mejorar el rendimiento, demostrando su valioso aporte como recurso de apoyo en el desarrollo de clases más interactivas y donde la participación activa del educando será importante, lo que se plantea para el fortalecimiento del proceso educativo.

\section{Métodos}

De acuerdo con la metodología utilizada para la creación del blog educativo, se utilizaron principalmente algunas técnicas como la observación, la encuesta, y la entrevista, que ayudaron en la creación, diseño y estructuración del blog, así como en el registro de la información que permitió comprobar la perspectiva de docentes y estudiantes. Igualmente se consideró la validación del blog por parte de dos docentes especialistas, uno del área de Estudios Sociales y un experto en el área tecnológica.

Los datos recolectados a través de herramientas digitales, fueron procesados con la estadística descriptiva a través de formularios de Google, de los que se extrajo la información y luego fue expuesta a través de cuadros y gráficos que muestran de forma detallada la información resultante, la cual posteriormente fue interpretada y analizada, para finalmente llegara las conclusiones que permiten determinar el cumplimiento del objetivo planteado para este estudio.

En este orden de ideas, para la creación del blog para la enseñanza y aprendizaje en el área de Estudios Sociales en noveno año de Educación General Básica de la Unidad Educativa Juan Montalvo, se procedió de la siguiente manera:

- Primero: Crear una cuenta en Google en Gmail ingresamos y nos dirigimos a crear el blog escribimos un dominio: (https://blogeducativosocialesjm.blogspot.com/)

- Segundo: Una vez creado el blog se procede a colocarle el nombre. (Blog Educativo de Estudios Sociales).

- Elegir una plantilla: diseño general del blog. (Con estas tres actividades se completan las formas para crear el blog y así poder acceder al panel de control).

- Cuarto: Como acceder al blog. Lo cual se puede lograr de dos formas: 
1. La forma más sencilla es ir a la página principal del Blogger, presentarse y completar los formularios solicitados.

2. La otra opción es escribir la dirección completa del nuevo blog. (posteriormente se puede acceder escribiendo el nombre del blog en el buscados).

3. En lo que se prosigue a la presentación del blog educativo: después de crear el blog se ingresa con la contraseña y nombre de usuario; se agrega el correo al cual llegaran las notificaciones; se completan los nombres y datos del blog; se aceptan las condiciones legales. Luego se procede a registrar los datos de perfil de usuario de Bloggers; etapa de comprobación y finalmente se registra el perfil.

Una vez creado el blog, en este se encuentran, diversas pestañas, relacionadas a los recursos para ingresar (solicitud de nombre de usuario y contraseña); uso de cuenta (introducción de datos); tablero del blog; contenido del tablero; pestañas pertinentes; nuevas entradas de publicaciones en el blog y finalmente se procede a diseñar el blog con imágenes colores, tipo de letra, otros que le permitan personalizarlo, haciéndolo atractivo y motivador, tanto para los estudiantes, como para los compañeros docentes.

Una vez creado el blog y personalizado y ajustado al área educativa. Se pondrá a disposición del estudiante el cual encontrará toda la información publicada, comentarios contenidos, enlaces, pestañas, todo tipo de documento adjuntado y archivado en el blog y permiso si se le otorgan a cualquier individuo que colabore como administrador adjunto.

\section{Resultados}

Resultados de la aplicación del instrumento a los docentes, de los cual se obtuvo los siguientes resultados:

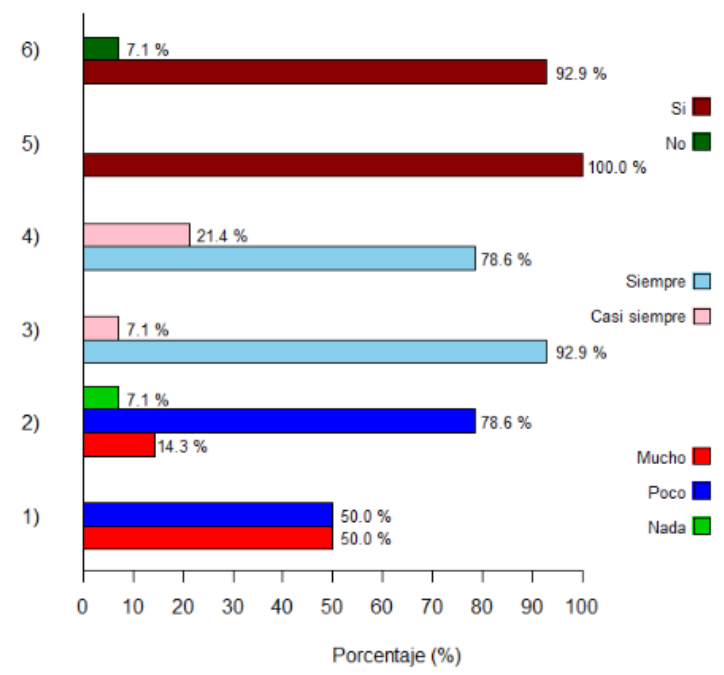

Figura 1. Resultados de las respuestas de los docentes sobre la implementación del blog educativo como herramienta didáctica en la enseñanza y aprendizaje para el área de Estudios sociales. 
Los resultados obtenidos permiten afirmar según las respuestas dadas por los docentes al ítem 1, que la mitad de los encuestados conocen las herramientas que se pueden incorporar como recurso en el proceso de aprendizaje; sin embargo, la misma proporción (50\%) señaló que no la conocen. Sobre el ítem 2, los docentes en un porcentaje bastante representativo $(78,6 \%)$ señalaron que utilizan una variedad de herramientas didácticas interactivas en la asignatura de Estudios Sociales. Para el ítem 3, un porcentaje alto $(92,9 \%)$ de los docentes consideró que el uso de un blog educativo resulta útil en el proceso de aprendizaje de Estudios Sociales. Sobre el ítem 4 se obtuvo que un alto porcentaje $(78,6 \%)$ de los docentes consideró que el uso de un blog educativo promueve la interacción entre grupos de profesores, estudiantes o comunidades de aprendizaje. En cuanto al ítem 5, se obtuvo que el total de la muestra (100\%) considera que la metodología de trabajo apoyada en herramientas didácticas tecnológicas es altamente beneficioso para la enseñanza aprendizaje de Estudios Sociales. Mientras que para el ítem 6, los docentes en un alto porcentaje $(92,9 \%)$ están dispuesto a incorporar una herramienta tecnológica didáctica digital en las clases de Estudios Sociales.

Resultados del instrumento aplicado a los estudiantes, de los cual se obtuvo los siguientes resultados:

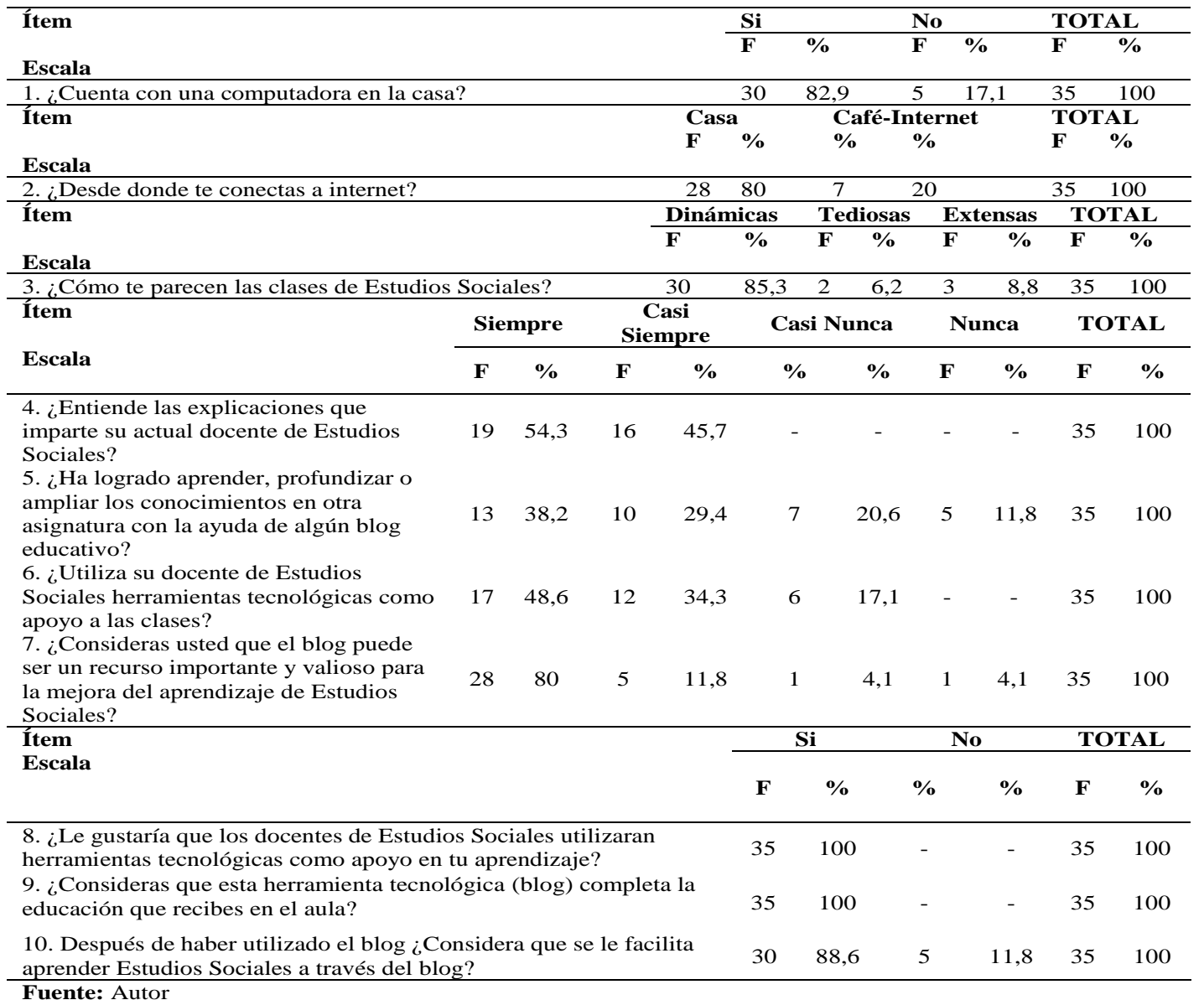




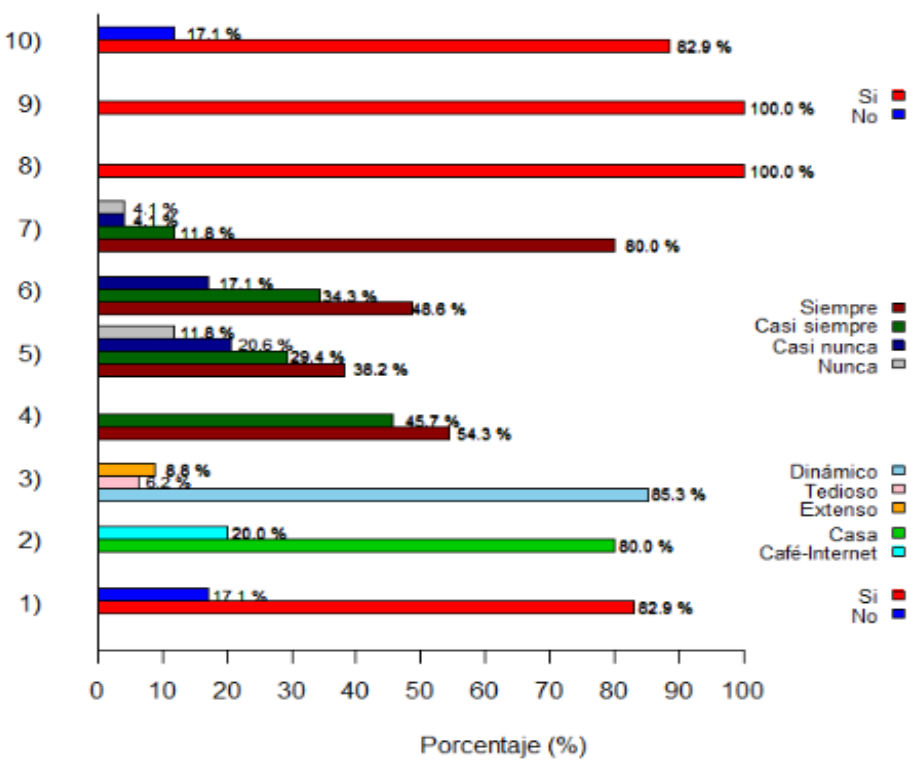

Figura 2. Resultados de las respuestas de los estudiantes sobre la implementación del blog educativo como herramienta didáctica en la enseñanza y aprendizaje para el área de Estudios sociales

Según las respuestas al ítem 1 de la encuesta aplicada a los estudiantes un porcentaje bastante alto $(82,9 \%)$ y sobre el ítem 2 , señalaron que cuenta con una computadora en la casa con acceso a internet. Las respuestas al ítem 3, dadas por los estudiantes encuestados muestran que un porcentaje alto $(85,3 \%)$ coinciden en señalar que las actividades en clase de Estudios Sociales son dinámicas, pero es importante el porcentaje de ellos que no se encuentran a gusto con las mismas, pues el 8,8\% las considera tediosas y el 6,2\% señaló que son extensas. Para el ítem 4, un porcentaje bastante representativo $(54,3 \%)$ coincidió en señalar que casi siempre entiende las explicaciones que imparte su actual docente de Estudios Sociales, mientras que el 45,7\% enfatizó en que siempre.

En cuanto al ítem 4, se obtuvo según las respuestas dadas por los estudiantes donde el 38,2\% señaló que siempre ha logrado aprender, los conocimientos en otra asignatura con la ayuda de algún blog educativo, el $29,4 \%$ enfatizo en casi siempre, el 20,6\% en casi nunca y el 11,8\% en nunca. Para el ítem 5, los resultados muestran que el 82,9\% de los alumnos señaló que su docente de estudios sociales utiliza siempre tendiendo a casi siempre herramientas tecnológicas como apoyo a las clases; sin embargo, el 17,1\% afirmó que casi nunca las utilizan.

Según las respuestas al ítem 6, al indagar la disposición de los estudiantes en cuanto a si les gustaría que sus docentes incorporaran herramientas tecnológicas en su proceso educativo, la totalidad de la muestra encuestada mostró disposición, lo cual ratifica que el escenario es propicio para que los educadores incorporen estas nuevas estrategias a su trabajo didáctico. Para el ítem 8 las respuestas de los estudiantes en su totalidad consideran que esta herramienta tecnológica (blog) completa la educación que recibes en el aula.

En relación a las respuestas de las estudiantes para el ítem 9, se obtuvo que un alto porcentaje $(80 \%)$ coincidió en señalar que el blog puede ser un recurso importante y valioso para la mejora 
del aprendizaje en Estudios Sociales. De igual manera sobre el ítem 10, el 80\% de los estudiantes manifestó que el uso del blog educativo creado para el proceso de enseñanza y aprendizaje, contribuyó a su proceso de estudio de los contenidos desarrollados en el área de Estudios Sociales.

\section{Discusión}

Una vez interpretado los resultados de las encuestas realizadas a estudiantes y docentes se establece solo la mitad de los encuestados conocen las herramientas que se pueden utilizar como recursos en proceso educativo, a este respecto se tiene que se deben establecer mecanismos de actualización docente en la capacitación en herramientas tecnológicas, aun cuando señalan que utilizan una variedad de recursos didácticos interactivos en la asignatura de Estudios Sociales. Puesto que se busca que los docentes puedan utilizarlas estas herramientas como recursos didácticos en apoyo al desarrollo de las clases, específicamente el blog educativo, el cual se considera que resulta útil en el proceso de enseñanza aprendizaje de Estudios Sociales, apoyándose en que los docentes están dispuesto a incorporarlo en el desarrollo de las clases de la asignatura de Estudios Sociales; ya que esta es una herramienta altamente efectiva con la que se promueve la interacción entre grupos de profesores, estudiantes o comunidades de aprendizaje en el logro del conocimiento.

Según los resultados del instrumento aplicado a los estudiantes, se obtuvo que la mayoría cuenta con una computadora en la casa, así como su acceso a internet, lo que es importante ya que la mayoría dispone de los recursos para lograr la realización del trabajo a través del blog desde su hogar. Se encontró también que, aunque la mayoría señalo que las clases de Estudios Sociales es dinámica, es importante destacar que un porcentaje de ellos, que no se encuentran a gusto con las mismas, lo que induce a generar cambios en la forma y la manera de impartir estas clases. Así mismo señalaron que entiende las explicaciones que imparte su actual docente de Estudios Sociales, y que han logrado que sea conocido por otros docentes los conocimientos en otra asignatura con la ayuda del blog educativo, de igual modo manifestó que el docente de estudios sociales utiliza siempre herramientas tecnológicas como apoyo a las clases.

Los estudiantes ratificaron la necesidad de que los docentes incorporaren herramientas tecnológicas para su trabajo didáctico; por lo que consideraron que el blog educativo es uno de estos recursos, que más contribuye a complementar el trabajo que se desarrolla en el aula, por lo que se considera que sea un medio importante y valioso para la mejora del aprendizaje de estudios sociales, contribuyendo a su proceso de formación y por ende del logro de la calidad educativa.

\section{Conclusiones}

- Según el objetivo planteado para el desarrollo del presente estudio, acerca de implementar una herramienta didáctica para el proceso de enseñanza aprendizaje de Estudios Sociales mediante un blog educativo en noveno año de Educación General Básica, se obtuvo que la tecnología es un medio por el cual se agrega cambios, innovación y transformaciones efectivas al proceso de formación académica, a través del fortalecimiento del conocimiento en todas las áreas. Por lo que en la actualidad por 
intermedio de las TIC se pueden buscar y lograr mejores estrategias de enseñanza y aprendizaje para complementar, estructurar y organizar los contenidos básicos de aprendizaje, sobre todo en áreas que resultan tediosas y extensas para los estudiantes como Estudios Sociales.

- Por lo que se evidenció que mediante la aplicación del blog educativo, para Estudios Sociales se ha logrado en gran medida despertar los estudiantes el interés de los estudiantes hacia el empoderamiento del conocimiento, y evidentemente demostraron una gran motivación en la adquisición de aprendizajes en esta área; lo que se ha evidenciado en las entradas frecuentes al blog y el mejoramiento del rendimiento académico ha mejorado notablemente debido a la buena gestión del contenido y actividades académicas desarrolladas y socializadas en clase.

- Por cuanto, a través de esta experiencia, el recurso digital (blog) se puede incorporar en otras áreas para abordar los contenidos que se imparten y contribuir en la formación integral del educando con la implementación de recursos y estrategias innovadoras que despierten el interés por aprender de una forma diferente, transformando la manera en la que se desarrollan las clases, para lo que se requiere en primera instancia capacitar y a los docentes en el manejo de las herramientas tecnológicas, así como contar con estos recursos para llevar a cabo las innovaciones que se requieren adicionar al proceso educativo.

\section{Referencias Bibliográficas}

Buxarrais, M. (2016). Redes sociales y educación. Education in the Knowledge Society, 17(2), 1520.

Carbonero, M., Martín, L., Flores, V., \& Resende, A. (2017). Estudio comparado de los estilos de enseñanza del profesorado universitario de ciencias sociales de España y Brasil. Revista Complutense de Educación, 631.

Gonzàlez, L. (2018). Educación y tecnología: estrategias didácticas para la integración de las TIC. Madrid : UNED.

Gutiérrez, R., Martínez, M., Bravo, J., \& Bravo, J. (2015). Tecnologías emergentes para la enseñanza de las Ciencias Sociales. Una experiencia con el uso de Realidad Aumentada en la formación inicial de maestros. Digital Education Review, 21(1), 138-153.

Hernandez, R. (2017). Impacto de las TIC en la educación: Retos y Perspectivas. Propósitos y representaciones, 5(1), 325-347.

Hernández, R., Fernández, C., \& Baptista, P. (2014). Metodología de investiogación (6a. Ed. ed.). España: Mc Graw Hill.

Ordoñez, A., Perez, L., \& Rzonzew, D. (2016). Las Prácticas de Lectura en Grado Quinto: Una Mirada en la Didáctica de las Ciencias Sociales. Bogotá : Universidad Pedagógica 
Nacional - Facultad de Educación - Departamento de Psicopedagogía - Licenciatura en Psicología y Pedagogía.

Osorio, Y., \& Díez, A. (2017). La enseñanza y aprendizaje de las Ciencias Sociales y el Desarrollo del Pensamiento Social . Colombia : Universidad Tecnológica de Pereira - Facultad de Educación - Maestría en Educación.

Pulido, E., Cuta, O., \& Geijo, P. (2016). Estilos de enseñanza y rendimiento académico. Journal of Learning Styles, 9(18), 1-20.

Rodríguez, Y., \& Mulet, A. (2016). Los blogs educativos como recurso didáctico en el proceso de enseñanza-aprendizaje de la historia. Revista Boletín Redipe, 5(9), 73-81.

Zallas, E., Choquijimse, Y., Falcón, L., \& Solano, C. (2018). Uso y actitudes de los profesores ante las tic, análisis de universidades públicas del Sur de Sonora. Revista de Investigación Académica Sin Frontera: División de Ciencias Económicas y Sociales, 23(1), 1-23.

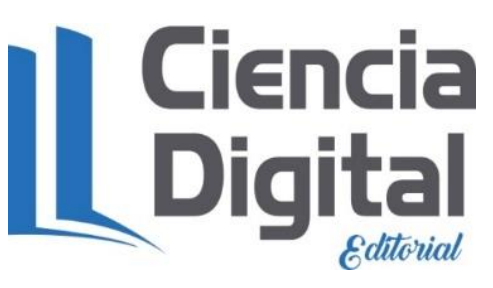




\section{Para citar el artículo indexado.}

Troya Torres, C., Quishpe Cusi, J. C., \& Parra Balza, F. (2019). El Blog como Herramienta Didáctica en el proceso de Enseñanza Aprendizaje de Estudios Sociales. Explorador Digital, 3(4), 29-42. https://doi.org/10.33262/exploradordigital.v3i4.913

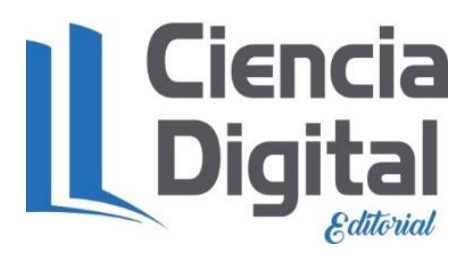

El artículo que se publica es de exclusiva responsabilidad de los autores y no necesariamente reflejan el pensamiento de la Revista Explorador Digital.

El articulo queda en propiedad de la revista y, por tanto, su publicación parcial y/o total en otro medio tiene que ser autorizado por el director o editor de la Revista Explorador Digital.

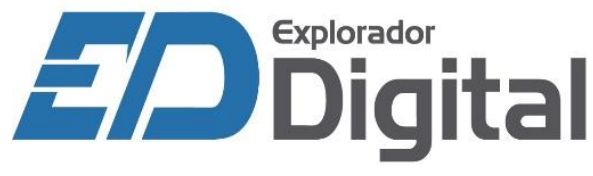

